\title{
Can Cheiromancy Predict Mean Survival or Fatality of a Patient with Amyotrophic Lateral Sclerosis?
}

\author{
Akshay Anand ${ }^{1, *}$ Sudesh Prabhakar ${ }^{1} \quad$ Keshav Thakur ${ }^{1, *}$ \\ Devi Prasad Tripathi ${ }^{3}$ Suresh Sharma ${ }^{4}$ \\ ${ }^{1}$ Department of Neurology, Neuroscience Research Lab, \\ Postgraduate Institute of Medical Education and Research, \\ Chandigarh, India \\ ${ }^{2}$ Faculty of Arts, Jyotirvigyan Kendra, Rajasthan University, Jaipur, \\ India \\ ${ }^{3}$ Department of vastushastra, Lal Bahadur Shastri Rashtriya Sanskrit \\ Vidyapeetha, New Delhi, India \\ ${ }^{4}$ Department of Statistics, Panjab University, Chandigarh, India
}

Rahul Tyagi ${ }^{1}$ Vinod Shastri²

\begin{abstract}
Address for correspondence Akshay Anand, PhD, Department of Neurology, Neuroscience Research Lab, Postgraduate Institute of Medical Education and Research, Chandigarh 160012, India (e-mail: akshay1anand@rediffmail.com).
\end{abstract}

J Neurosci Rural Pract 2020;11:256-260

\begin{abstract}
Keywords

- ALS

- cheiro

- palmistry

- survival time

Background The past three decades have seen palmistry as an interface to human health. There have been no previously organized attempts in utilizing this knowledge to predict the state of disease.

Objective Due to unavailability of any biological marker for diagnosing amyotrophic lateral sclerosis (ALS) till date, we attempt to examine whether palmistry could be used for detecting the onset and survival of patient suffering from ALS.

Methods Patients suffering from ALS attending the neurology outpatient department at Postgraduate Institute of Medical Education and Research, India were selected for study. Palm photographs were obtained from all patients including controls after their consent. Patients suffering from other comorbidities such as diabetes, hypertension, migraine, as well as smokers and nonsmokers were included in the study. Twenty-six ALS patients, 30 neurological controls, and 34 healthy age matched controls were recruited in the study. Retrospective analysis of the palm pictures based on blinding method was performed by academically qualified palmists.

Results The results demonstrated the need for further studies in the subject even though the observations made were independent by both the palmists.

Conclusion This study opens new vistas for cheiromancy to be further explored for analysis in larger samples.
\end{abstract}

\section{Introduction}

Palmistry is generally considered as an occult science. Believed to have originated in India, it spread from Asia and the whole world with time. William John Warner, also known as Cheiro, was an Irish astrologer who learned palmistry in India and later spread it to Europe. A term cheiromancy was coined after William John Warner. Although not much literature exists consisting of studies using palmistry as a diagnostic tool for disease onset, however, certain studies have used

*Akshay Anand and Keshav Thakur contributed equally to this study. palmistry or dermatoglyphic as one of the tools for predicting the disease onset. ${ }^{1,2}$ Palmistry employs the study of line to predict disease mind. ${ }^{3,4}$ Bhargava and Sathawane in 2012 suggested that dermatoglyphics can find its application in medical diagnosis of various diseases through invention of new or unusual patterns. ${ }^{5,6}$ This makes description of certain crease, curves and lines defined as heart line, head line, life line, simian crease, Sydney crease, etc. ${ }^{2-4}$ hold a significant value and based on this, the palmists or any cheirologist may suggest the current position of an individual. However, one should 
not confuse between the palmistry and dermatoglyphic as the latter is considered as more scientific method of analyzing and correlating the crease and palm patterns with the genetics of disease. The patterns obtained from fingerprints are related to different disorders uniquely. In context to dermatoglyphics, several theories have been proposed to investigate the hand patterns in diseased patients. First theory came up in 1924 by Bonnevie, discussing the formation of patterns and crease on palms. ${ }^{7}$ Later Cummins in mid-1950s tried to find the relation between palm patterns as well as geometry of palm. ${ }^{8}$ Cummins' theory is still considered for analysis of hands and foot today. ${ }^{9}$ Recently, in 2013, Kücken and Champod have tried to explore the relation between stress factor's impact and geometry of feet and hands. ${ }^{10}$ In current study, we have attempted to examine the relation of palm morphology with survival in amyotrophic lateral sclerosis(ALS) patients. It had been for the first time that science of palmistry is being tested for predicting the disease condition and the survival of patient to verify whether it can be used as a tool to diagnose the onset and time the patient will live after onset of disease.

\section{Materials and Methods}

Data analysis was performed in Neuroscience Research Lab, Postgraduate Institute of Medical Education and Research, India.

\section{Study Design}

Patients recruitment: ALS patients were recruited from outpatient department of neurology, Postgraduate Institute of Medical Education and Research, Chandigarh, India. Age and sex matched controls were also obtained from the hospital. A total of 90 subjects were selected out of which 26 ALS, 30 neurological controls, and 34 age matched healthy controls were recruited.

Analysis: A retrospective analysis was performed on the palm pictures captured from all the above-mentioned subjects after obtaining informed consent. These palm pictures were stored electronically after proper coding. Study was ethically approved by institutional ethical committee.

Blinding: Blinding was done for palm pictures as per laboratory's established protocol and was provided to the palm analysts for further interpretation. Palmists were not aware of the status of patients as to which disease are they suffering from. No prior information about status of palm pictures was provided to palmists (thus reducing the potential bias for ALS in palmistry). These images were analyzed independently by the palmists ( - Fig. $\mathbf{1}$ ).

\section{Palm Analysis}

Palm analysis was performed by two academically qualified $(\mathrm{PhD})$ palmists. Both were given same set of data and were asked to analyze the images ( $\mathbf{- T a b l e} \mathbf{1}$ ).

Physical signs and symptoms on palm decide about disease and death of an individual. ${ }^{11}$ Palm is of different shapes such as square, rectangular, circular, rukshakriti (bear shape), and cow's mouth shape. ${ }^{11-14}$
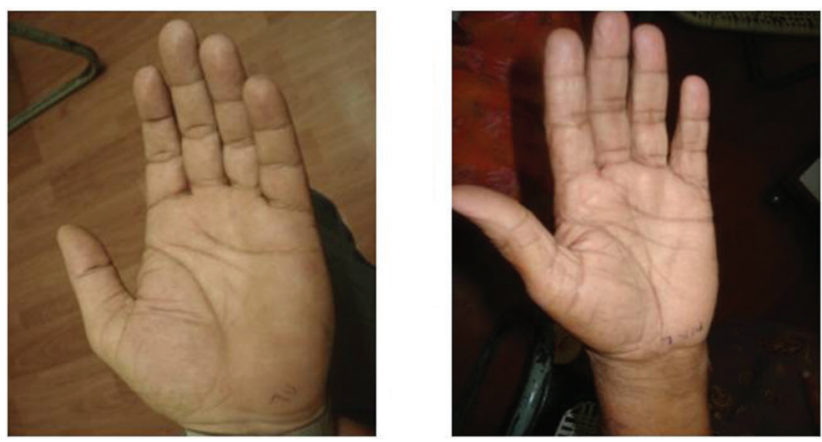

Fig. 1 Representative palm pictures of subjects that were provided to palm analyst for predicting their health condition and their survival tenure.

An individual with square palm and nails with a bit of pale blue color indicates that person's lifespan can be extended with drugs only. Normally, person with square palm stick to their own work but due to branching of heart line on the mount of Venus indications for brain disease especially brain hemorrhage may be the cause of person's death.

A rectangular palm of stiff or rough appearance indicates lung infection may become reason for death.

If the life line of dying person's palm is intersected by islands or diagonal lines, then heart problem brain disease or any kind of accident becomes a reason for death.

Rough skinned palm with blue color nail characters results in heart problems and brain hemorrhage due to uninvited tensions. However, if nails are curved outward with redness than that person is predicted to have long life, but if sun line is intersected by a line from the mount of Venus going toward heart line is an indicator of high cholesterol levels in body and signals paralysis and vision loss of that individual (-Table 2 ).

Interpretation of lines as per the palmists are as follows: $:^{11,12}$

1. If heart line goes till mount of Saturn and divides into two parts by getting into a shape of an island before reaching the mount of Saturn, then it indicates that patient might die of lung infection during surgical procedure.

2. If head line is being intersected by Saturn line and later head line is branched into three parts, then it indicates the death of person due to delayed diagnosis or due to some surgical error.

Later, the information from palmists was matched with the data which were obtained from ALS patients. These data were not shown to palmists; neither the nature of subject nor age, sex, etc. was disclosed. Comorbidities were also taken into account to understand if they have any impact on subject's survival ( - Table 3 ).

Patients were later contacted by telephone to know the status of their survival by team members of Neuroscience Research Lab.

\section{Statistical Analysis}

Statistical analysis was performed using nonparametric tests (Kaplan-Meier and Mann-Whitney) to compare the analysis done by palmists. Apart from this analysis was performed to check whether how much the information provided by 
Table 1 Names and description of creases present on palm along with their position in the image

\begin{tabular}{|c|c|c|c|}
\hline S. No. & Name of lines & Description & Position of line in palm \\
\hline 1. & Hridayrekha (heart line) & Heart line originates from small finger up to index finger & \\
\hline 2. & Mstishkrekha (head line) & $\begin{array}{l}\text { Head line although below heart line originates at the } \\
\text { center of index finger and thumb and moves toward } \\
\text { moon mount on the palm }\end{array}$ & \\
\hline 3. & Life line & $\begin{array}{l}\text { Life line originates from the center of index finger and } \\
\text { thumb and extends through the middle of palm making } \\
\text { a semicircle till the base of thumb }\end{array}$ & \\
\hline 4. & Suryrekha & $\begin{array}{l}\text { Sun line originates at the base of ring finger till the base } \\
\text { of sun mount just above the heart line }\end{array}$ & \\
\hline 5. & Fate line & $\begin{array}{l}\text { Fate line originates from the base of thumb till the base } \\
\text { of middle finger }\end{array}$ & \\
\hline 6. & Mercury (business) line & $\begin{array}{l}\text { Mercury line originates from the base of thumb and } \\
\text { extends up to small finger }\end{array}$ & \\
\hline
\end{tabular}

Table 2 Different color of palm indicates impact on health condition of an individual

\begin{tabular}{|l|l|l|l|}
\hline S. No. & Palm color & Indication & Time span \\
\hline 1. & Blue & Death due to infectious disease & Not defined \\
\hline 2. & Black tone & Death & $15 \mathrm{~d}$ \\
\hline 3. & Light yellow colored & Heart/brain disease & $30 \mathrm{~d}-3 \mathrm{y}$ \\
\hline 4. & Redness & Recovery from heart disease & Not defined \\
\hline 5. & White/light red palm & Immediate death or dead person & Not defined \\
\hline 6. & Bright blue palm & Fast recovery from surgical procedure & Not defined \\
\hline
\end{tabular}

Note: This table describes the color difference along with their indication and possible time limit in which the individual may get affected.

palmist match with phenotype of ALS in patients recruited for study.

\section{Results}

Analysis of results showed results which need to be further validated in larger sample. The observations were made independently by two palmists. The data from first palmist showed $15.4 \%$ prediction of fatality for ALS subjects with $3.85 \%$ similarity to ALS phenotype, as compared with $40 \%$ accurate prediction of ALS phenotype and only $24 \%$ of fatality in ALS patients as per the second palmist (-Table 4).

When we performed the survival analysis of the ALS patients, significant difference $(p=0.047)$ was observed between median survival times by the palmists as compared with actual lifespan of ALS patients, calculated by patient follow-up (-Fig. 2). 
Table 3 List of comorbidities taken into account while analyzing the palm pics

\begin{tabular}{|c|c|c|}
\hline \multicolumn{3}{|c|}{ Comorbidity } \\
\hline & Heart disease & 12. Obese/overweight \\
\hline 2. & $\begin{array}{l}\text { Diabetes/autoimmune } \\
\text { disease }\end{array}$ & 13. No comorbidity \\
\hline 3. & Hb/other blood disease & 14. Migraine/headache \\
\hline 4. & Liver disease & 15. Underweight \\
\hline & $\begin{array}{l}\text { Frontal stress/brain related } \\
\text { problems/depression/ } \\
\text { paralysis }\end{array}$ & $\begin{array}{l}\text { 16. Sleep problem/men- } \\
\text { tal trauma }\end{array}$ \\
\hline 6. & Kidney disease & $\begin{array}{l}\text { 17. Abnormal blood } \\
\text { pressure }\end{array}$ \\
\hline & Coma & 18. Eye disease \\
\hline & Age-related problems & 19. Memory deficits \\
\hline 9. & Terminal Illness & $\begin{array}{l}\text { 20. Breathing trouble/ } \\
\text { respiratory issues }\end{array}$ \\
\hline 10. & $\begin{array}{l}\text { Intense pain resulting } \\
\text { death }\end{array}$ & $\begin{array}{l}\text { 21. Arthritis/joint } \\
\text { diseases }\end{array}$ \\
\hline 11. & Thyroid problem & \\
\hline
\end{tabular}

\section{Discussion}

Palm reading or palmistry, also called as cheiromancy (meaning hand prediction) in older times, is an analysis of a person's hand to foretell the future aspects of life including health outcomes. Health-related predictions such as diseases and ailments have also been studied since long time, and there are various studies that indicate the relation between palms and physical well-being ${ }^{11}$; however, most of such studies are not designed scientifically. Mount of Venus and heart line are considered as a representative of warnings for diseases related to heart, kidney, diabetes, urinal tract, and mental depression, while various other diseases such as familial deafness, leprosy, and rheumatoid arthritis have been believed to be related to the simian line. ${ }^{12,13}$ As such, in current study, astrologers have taken into consideration the line and physical appearance of palm for deducing an observation over a patient. They have highlighted the importance of lines and mounts and also defined how analyzing the lines can help in predicting the condition of a patient. It is believed that analyzing the palm pictures the person's nature and lifestyle can be predicted. ${ }^{14}$ The palm lines are also used to predict human life's bad or good events as well as various diseases

Table 4 Data obtained from two palmists on the health and phenotype of ALS patient

\begin{tabular}{|l|l|l|l|l|}
\hline & $\begin{array}{l}\text { Correct prediction of } \\
\text { diseased organ for ALS }\end{array}$ & $\begin{array}{l}\text { Correct prediction of } \\
\text { fatality for ALS }\end{array}$ & $\begin{array}{l}\text { Correct prediction of } \\
\text { diseased organ for } \\
\text { neurological controls }\end{array}$ & $\begin{array}{l}\text { Correct prediction of } \\
\text { diseased organ for } \\
\text { normal controls }\end{array}$ \\
\hline Observer 1 & $1 / 26=3.85 \%$ & $4 / 26=15.4 \%$ & $5 / 27=18.5 \%$ & $1 / 34=2.94 \%$ \\
\hline Observer 2 & $10 / 25=40 \%$ & $6 / 25=24 \%$ & $4 / 30=13.3 \%$ & $1 / 34=2.94 \%$ \\
\hline
\end{tabular}

Abbreviation: ALS, amyotrophic lateral sclerosis.

Survival Functions

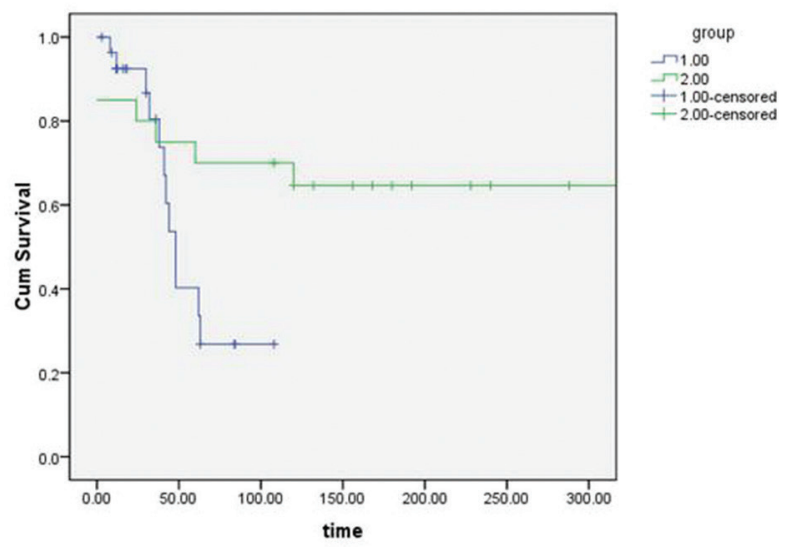

Fig. 2 Survival analysis curve of ALS patients. Blue line indicates actual lifespan and green line indicates lifespan of ALS patients according to the palmists. ALS, amyotrophic lateral sclerosis.

Actual lifespan was confirmed telephonically by the neuroscience research team. The cumulative survival curves (Kaplan-Meier) show that, after 5 years, the actual survival was only $25 \%$, while that predicted by palmist was $70 \%$. and accidents. Currently available literature about palmistry and its scientific application are a result of scientific analysis performed on the palm contours of diseased patients. ${ }^{14-16}$ In 2011, a study published in International Journal of Morphology associated the chromosomal aberration with pattern of simian and Sydney lines or life line and head line. ${ }^{4}$ In support, similar observation with context to palm creases has been made in current study where palmists reported that palms having branching of heart line on the mount of Venus indicate brain disease or brain hemorrhage. Karnick in one of his article cited the work of Dobson et al where they have tried to examine the correlation between the palmar keratoses and any form of cancer. They found an association with $46 \%$ palms of men and $28 \%$ women, as compared with only $12 \%$ of normal men and $5 \%$ of normal women. Another study was reported in 1990 where these palmar keratoses were studied in association with bladder cancer. ${ }^{18}$ Newrick et al found a strong relationship between length of life line and age. They evaluated 100 autopsies and found that length of right hand life line and age at death were statistically correlated even though according to Karnick, person's longevity is influenced by the heart line. ${ }^{1,19}$ Various other studies have associated dermatoglyphic patterns with dental caries, ${ }^{20}$ gynecological cancers, ${ }^{21}$ autism, ${ }^{22}$ nonsyndromic cleft lip, ${ }^{23}$ 
and breast cancer. ${ }^{24,25}$ In current study, the palmist took into consideration the color pattern, tone of palm, as well as skin pattern of palm in predicting the survival and condition of patient. As a result, initially both observers were able to give $40 \%$ correct prediction of diseased organ with palms of ALS patients (palm pictures were blinded to the observer). The fatality prediction for ALS patients of both the observers did not match the actual data. As per observer's record, 15.4\% for observer 1 and 24\% of patient were predicted to die soon due to some brain-related disorder. On performing the statistical analysis, we observed the significant difference of $p=0.047$. In Kaplan-Meier's survival analysis, palmist observations reported the survival of up to $70 \%$ among ALS patients, whereas the actual survival was only $25 \%$. The current study suffers from a limitation. The palm pictures were available in JPEG format and no real-time observations or interactions were allowed. Such analysis can be extended to other fatal diseases and its role in predicting the disease condition in an individual can be similarly ruled out before concluding that palmistry does not hold significance in health care.

\section{Authors' Contributions}

A.A. contributed to study design and editing, S.P. screened the ALS patients, S.S. was involved in statistical analysis and interpretation of data. V.S., K.T., and R.T. acquired and compiled the data and K.T. prepared the preliminary draft of the manuscript.

\section{Conflict of Interest}

A.A. reports grants from ICMR, during the conduct of the study.

\section{Acknowledgments}

We acknowledge Dr. Vinod Shastri and Dr. D. P. Tripathi for their support in palm prediction and analysis. We also thank Dr. Kaushal Sharma and Miss Radhika for their support.

\section{References}

1 Karnick CR. Some correlation between onset of specific diseases and indication system in skin and lines of human palm. Anc Sci Life 1987;7(1):17-20

2 Madan N, Rathnam A, Bajaj N. Palmistry: a tool for dental caries prediction! Indian J Dent Res 2011;22(2):213-218

3 Sharma A, Somani R. Dermatoglyphic interpretation of dental caries and its correlation to salivary bacteria interactions: an in vivo study. J Indian Soc Pedod Prev Dent 2009;27(1):17-21

4 Sharma DK, Sharma V. Prevalences of simian, Sydney and Suwon creases and their association with each other, body sides, handedness, sex and anomalies/diseases/syndromes in a population of Central India. Int J Morphol 2011;29: 1069-1075
5 Bhargava SS, Sathawane RS. Dermatoglyphics - exploring newer dimensions in diagnosis. Central India Journal of Dental Sciences 2012;3:2

6 Shanmugapriya B, Rajesh R. Survey: applications of bravura information in human hand. International Journal of Wisdom based Computing 2011;1:19-23

7 Bonnevie K. Studies on papillary patterns in human fingers. J Genet 1924;15:1-111

8 Cummins H. Epidermal-ridge configurations in developmental defects, with particular reference to the ontogenetic factors which condition ridge direction. Am J Anat 1926;38:89-151

9 Kücken M. Models for fingerprint pattern formation. Forensic Sci Int 2007;171(2-3):85-96

10 Kücken M, Champod C. Merkel cells and the individuality of friction ridge skin. J Theor Biol 2013;317:229-237

11 Fakoya AOJ, Otohinoyi DA, Marcelle T, Yusuf J. The palmheart diameter: a prospective simple screening tool for identifying heart enlargement. Open Access Maced J Med Sci 2017;5(7):818-824

12 Dale HF. Indian Palmistry. White Press Publisher; 2016

13 Ghai N, Palm Guide: An Easy Way to Learn Palmistry. Books for All. India: Low Price Publications; 2009

14 Penrose LS. Fingerprints and palmistry. Lancet 1973;1(7814): 1239-1242

15 Frith H. Chiromancy; or, The Science of Palmistry - Scholar's Choice Edition. Creative Media Partners, LLC; 2015

16 Ahmed-Popova FM, Mantarkov MJ, Sivkov ST, Akabaliev VH. Dermatoglyphics-a possible biomarker in the neurodevelopmental model for the origin of mental disorders. Folia Med (Plovdiv) 2014;56(1):5-10

17 Dobson RL, Young MR, Pinto JS. Palmar Keratoses and Cancer. Arch Dermatol 1965;92(5):553-556

18 Cuzick J, Babiker A, De Stavola BL, McCance D, Cartwright R, Glashan RW. Palmar keratoses in family members of individuals with bladder cancer. J Clin Epidemiol 1990;43(12):1421-1426

19 Newrick PG, Affie E, Corrall RJ. Relationship between longevity and lifeline: a manual study of 100 patients. J R Soc Med 1990;83(8):499-501

20 Ramani P, Sentamilselvi G, Narayan V, et al. Reliability of specific finger dermatoglyphic patterns and their association with dental caries. Gen Dent 2014;62(5):e9-e11

21 Abbasi S, Rasouli M. Dermatoglyphic patterns on fingers and gynecological cancers. Eur J Obstet Gynecol Reprod Biol 2018; 222:39-44

22 Walker HA. A dermatoglyphic study of autistic patients. J Autism Child Schizophr 1977;7(1):11-21

23 Scott NM, Weinberg SM, Neiswanger K, et al. Dermatoglyphic pattern types in subjects with nonsyndromic cleft lip with or without cleft palate $(\mathrm{CL} / \mathrm{P})$ and their unaffected relatives in the Philippines. Cleft Palate Craniofac J 2005;42(4):362-366

24 Okra Podrabinek N, Roudier M, Lamour Y, de Grouchy J. Dermatoglyphic patterns in senile dementia of Alzheimer's type. Ann Genet 1988;31(2):91-96

25 Chintamani, Khandelwal R, Mittal A, et al. Qualitative and quantitative dermatoglyphic traits in patients with breast cancer: a prospective clinical study. BMC Cancer 2007;7(7):44-45 